\title{
A Comparative Study on Speech Acts: Formal Complaints by Native Speakers and Turkish Learners of English
}

\author{
Okan Önalan a * (D), Abdulvahit Çakır b† (D) \\ a National Defense University, Ankara, 06654, Turkey \\ ${ }^{b}$ Gazi University, Ankara, 06830, Turkey
}

Received 3 April 2018 | Received in revised form 13 August 2018 | Accepted 7 September 2018

\begin{abstract}
APA Citation:
Önalan, O., \& Çakır, A. (2018). A comparative study on speech acts: formal complaints by native speakers and Turkish learners of English. Eurasian Journal of Applied Linguistics, 4(2), 239-259. doi: 10.32601/ejal.464128
\end{abstract}

\begin{abstract}
The aim of this study is to investigate the pragmatic language behavior of Turkish learners of English in formal complaint situations through the comparison of their speech act performances to those of native speakers. The data was collected from a total of 276 participants, 132 Native Speakers (NSs) and 144 Turkish Learners (TLs) of English. Three different data collection methods were used: a) Discourse Evaluation Task (DET); b) video-recorded role plays; and c) open-ended oral interviews. The results indicate that native English speakers' and Turkish learners' production of complaints reflects a significant difference with respect to the linguistic components and the pragmatic choices made in complaining. A significant contribution of the current study to the literature is the Discourse Evaluation Task (DET), which is both a data collection tool and a term used for the first time in this paper.

(C) 2018 EJAL \& the Authors. Published by Eurasian Journal of Applied Linguistics (EJAL). This is an open-access article distributed under the terms and conditions of the Creative Commons Attribution license (CC BY-NC-ND) (http://creativecommons.org/licenses/by-nc-nd/4.0/).
\end{abstract}

Keywords: Speech acts; formal complaints; directness-indirectness; pragmatic competence; discourse evaluation task (DET)

\section{Introduction}

As long as languages have existed, there have also been cultures. Therefore, language learners' command of socio-cultural rules, which is widely known as pragmatic competence, plays a crucial part in successful communication, and learning a language involves acquiring pragmatic competence that entails appropriate ways of conveying communicative intent in a variety of situations. In other words, language learners should learn to speak not only grammatically, but also 'appropriately' to achieve communicative goals (Novick, 2000). This notion of 'appropriateness' emphasizes that second or foreign language learners ought to master not only

\footnotetext{
* Corresponding author.

E-mail address: okanonalan@gmail.com

† vahit@gazi.edu.tr
} 
linguistic rules such as morphology, syntax, phonology and vocabulary, but also the pragmatic rules of target language use. Tanck (2002) asserts that speakers who seem 'fluent' in a foreign language due to their expertise of the grammatical rules of that language and its vocabulary may still lack pragmatic competence; and as a result, they may not be able to produce language that is socially and culturally appropriate. Thus, language learning requires more than developing an extensive vocabulary, learning grammar, and acquiring native-like pronunciation.

It is significant to understand how foreign language learners (FLLs) interpret and produce speech acts (e.g. apologies, complaints, compliments, refusals, requests, suggestions, thanks, etc.) both in terms of socio-cultural and pragmatic appropriateness. Pragmatics underscores the significance of socio-cultural contexts in interpersonal and intercultural communication. Particular models and notions such as 'Speech Act Theory' (Searle, 1969) and 'Politeness Theory' (Brown \& Levinson, 1987) attempt to explain the significance of various socio-cultural factors in communication. In time, the focus of interest in the learner language in the field has evolved into a branch called 'interlanguage pragmatics' (House \& Kasper, 1987), which specifically discusses how non-native speakers (NNS) comprehend and produce a speech act in the target language and how their pragmatic competence (Bialystok, 1993) develops over time (Kasper \& Blum-Kulka, 1993). Research has mainly concentrated on establishing whether non-native speakers differ from native speakers (NS) in their use of strategies and linguistic forms to convey meaning and politeness. Centered on this significance, scholars of interlanguage pragmatics have been researching cross-cultural differences of speech act usage and second/foreign language learners' mastery of the speech acts (Cohen \& Olshtain, 1981; Takahashi \& Beebe, 1987; Cohen, 1996a; Cohen 1996b; Kasper, 2001; Tanck, 2002; Taguchi, 2011; 2012; 2015).

\section{Literature review}

Speech act research has been maturing, yet still needs to be expanded into a variety of languages and speech acts. Although there have been efforts (Kachru, 1991) to expand the line of research to different languages (Bergman \& Kasper, 1993 - Thai; Johnston, Kasper \& Rose, 1994; Mizuno, 1996; Arent, 1996; Du, 1995 - Chinese; Márquez Reiter, 2000 - Uruguayan Spanish; Blum- Kulka, 1982; 1983 - Hebrew), there still is a need to expand the research to different languages. Similarly, a great deal of research has been done on the speech acts of apologies and requests (Cohen \& Olshtain, 1981; Blum-Kulka \& Olshtain, 1986; Olshtain \& Cohen, 1983; Blum-Kulka, 1991; Ellis, 1992; Kim, 1995; Meier, 1998; Kasper \& Rose, 2001, Achiba, 2003; Barron, 2003; Hassall, 2003; Schauer, 2004, Félix-Brasdefer, 2007; Otcu \& Zeyrek, 2008; Flores Salgado, 2011; Göy, Zeyrek \& Otcu, 2012; Woodfield, 2010, 2012). Still, more systematic comparisons of cross-cultural pragmatic patterns, covering a broader range of languages and speech acts are required in order to uncover universal and culturespecific language behavior. 
This study investigates the pragmatic language behavior of Turkish learners of English in formal complaint situations through the comparison of their speech act performances to those of native speakers. By exploring Turkish EFL learners' speech production in Turkish and English, and comparing it to the data provided by native speakers, this study aims to (1) identify language use differences between Turkish and native speakers of English in complaining; (2) explain what pragmatic choices native speakers and Turkish learners make in their formal complaining attempts in English, and (3) account for factors such as 'gender' and 'length of stay in the target culture' that govern the communicative choices made by Turkish speakers of English in formal complaints.

The original contribution of the study to the literature is The Discourse Evaluation Task (DET), which is a data collection instrument and a term that has been used for the first time in this study. Furthermore, the current study lays out a particular level of understanding of the discrepancies that can exist between native and non-native complaints. Finally, language teachers and syllabus designers may use the current findings in order to explain complaint situations in which learners of English may fail pragmatically; and in turn, to develop materials and strategies to overcome such problems.

\section{Method}

\subsection{Preliminary baseline study}

In order to establish a baseline for this study and to specify the type of complaint to work with, a preliminary research was conducted. A survey (devised from Tanck, 2002) with a Discourse Completion Test (DCT) asked the participants to write their natural responses to three interactions with different levels of formality: studentprofessor (formal), neighbor-neighbor (semi-formal), and roommate-roommate (informal). A total of 16 subjects (8 native and 8 Turkish speakers of English) participated in the research. The responses were later analyzed and compared. Finally, the quality of directness in one of the components (namely 'request' as a part of complaint) was evaluated. Results showed a significant difference between the two groups in the 'student-teacher prompt' (formal complaint) in that all native speakers used mostly direct requests to deal with the situation whereas fewer and indirect requests were posed by the Turkish speakers in order to address their complaints in the situation. Moving from this framework, the study was limited to formal complaint situations. All throughout the study, the same scenario which involved a formal interaction of unequal power-relation between a student and a professor was used where necessary.

\subsection{Participants}

A total of 276 participants took part in the study: 132 Native Speakers (NSs) of English and 144 Turkish Learners (TLs) of English. Of the 132 NSs, 101 (76.5\%) were 
American, 21 (15.9\%) were British, 3 (2.3\%) were Canadian, 3 (2.3\%) were Australian, $2(1.45 \%)$ were Irish, and $2(1.6 \%)$ were Scottish. A significant number of the participants were students (68 NSs and $110 \mathrm{TLs})$ and teachers (21 NSs and $22 \mathrm{TLs})$. Of the $132 \mathrm{NSs}, 50$ (37.9\%) were male and 82 (62.1\%) were female. As to the 144 Turkish learners of English, $68(47.2 \%)$ were male and $76(52.8 \%)$ were female. Totally, 118 male and 158 female subjects took part in the study. All of the NS student participants were exchange students in different Turkish universities. Both native speakers (NSs) and Turkish learners (TLs) show a similar distribution in terms of their fields of education. $98 \mathrm{NSs}(74.2 \%)$ studied in one of the departments of either the 'School of the Humanities and Social Sciences' or the 'School of Arts and Humanities'. Similarly, 108 TLs (75\%) studied in a department that belongs to one of the two schools. As to the age profile of the subjects, the majority of the participants' age ranged between 18 and 50, except for the fact that only 13 NSs were 50 and above. A significant proportion of the participants (163 out of 276, 59\%) ranged from the ages of 18 to 24 . Specifically, 59 (44.7\%) NSs and 104 (72.2\%) TLs were between 18 and 24. The majority of the Turkish participants (84 TLs, 59.3\%) had 5 or more years of English instruction. A total of 114 TLs (79.2\%) never visited an Englishspeaking country.

\subsection{Data collection}

Three different data collection instruments were used in this study: a) Discourse Evaluation Task (DET); b) video-recorded role plays; and c) open-ended interviews.

\subsubsection{Discourse Evaluation Task (DET)}

The Discourse Evaluation Task (DET), which is a term that has been used for the first time in this study, is a particularly designed questionnaire by the researcher with a structured discourse evaluation and completion task that aims to minimize some of the observed limitations of the DCTs. Conventionally, DCTs have been used repeatedly in studies on speech acts to measure speakers' perceptions of what they would say in a given situation, yet they do not claim to be measures of authentic and actual oral production (Beebe \& Cummings, 1985, 1996). Typically, a written discourse completion task provides a scenario, followed by an empty slot for a response. It could also include one or two turns. On the other hand, The Discourse Evaluation Task form in this study (see Appendix) has four distinctive parts: 1) the informed consent, 2) demographic information about the participants, 3) discourse evaluation task made up of an instruction, the scenario, the beginning of the conversation, and a 5-Likert scale evaluation task with 10 possible requests as a part of complaint, and 4) a traditional discourse completion task that demands an openended response from the participants.

In the third part of this instrument, specifically, a short paragraph instructed the participants to read the given hypothetical situation. According to the situation, the speaker, a university student, receives an unexpectedly low final grade for a course and is about to make a verbal complaint to the course's teacher who is a 50-year-old 
male professor. Later, the task initiates the conversation. Next, as stated in the instructions, 10 possible responses to complete the rest of the dialog between the professor and the student were listed. Using the scale given after each question, the participants were asked to evaluate each response with regard to the extent they thought it would be socially acceptable/appropriate. The discourse evaluation tasks required that the 10 items be ranked on a five-point Likert scale, ranging from 'very rude' to 'perfectly appropriate'. In an effort to structuralize the responses given by the participants, the complaints were divided into four components and the third component was determined as a request. These requests as a part of complaint discourse were sometimes found to be direct and sometimes indirect depending on the strategy used by the complainer. In this framework, the discourse evaluation task provided the first two components as the beginning of the conversation and asked the participant to rate the 10 requests. A total of 10 request statements as a part of the complaint were chosen and devised using the responses from the preliminary study. Of the 10 statements, five statements (statements 1, 3, 5, 8 and 10) used direct requests whereas the other five (statements 2, 4, 6, 7 and 9) involved indirect requests as a part of the complaint in the given scenario.

\subsubsection{Video-recorded role plays}

In order to gather more data on formal complaints and validate the data collected by the DET, the participants were asked to complain verbally in a role-play setting, in which they were asked to act for the same scenario given in the discourse evaluation task. All NS participants were asked to take part, but only 16 participants (12 NSs and $4 \mathrm{TLs}$ ) volunteered to participate in the role plays. Since the participants were asked to complain to a university professor in the original scenario, a 53-year-old British native speaker acted as a professor to address the authenticity concerns. He was informed about the scenario in detail and precise instructions were given to him how to act as naturally as possible. The 16 participants were told that he was actually a university professor himself.

With the participants' permission, the role-plays were recorded using a digital video-recorder. So as to make the setting as natural as possible, the recordings were conducted in a lecturer office at a state university. Later the recorded role-plays were transcribed and complaint patterns analyzed. The data collected from the transcripts of the roleplays played a significant role in the triangulation (Wolfson, 1986) of the data collection process. What is more, since the role-play setting required the participants act instantly, without elaborate and prolonged consideration time, their complaint responses were to be more genuine compared to open-ended written scenario in the DET (Hartford \& Bardovi-Harlig, 1992). This helped the researcher to collect more realistic data as to the complaining patterns of both native and nonnative speakers. Although the data cannot be generalized to the whole sample group, the complaint patterns were found to be representative of both NSs and TLs especially when compared to the DET data. 


\subsubsection{Open-ended interviews}

Finally, with the aim of enriching the data gathered for the research and to justify the responses of the participants both in DETs and the video-recorded role plays, open-ended interviews were conducted. Although the shortcomings of interviews as a data elicitation technique cannot be overlooked and subjects may not say honestly what they think and instead give responses they think the researcher wants to hear, researcher's own bias, Seliger and Shohamy (1989) mention the following benefits of open-ended interviews: they allow for greater depth in obtaining information, and the interviewee has greater flexibility and freedom of expression. Cohen (1996c) highlights the power of verbal reports in obtaining "feedback from respondents regarding aspects of their behavior that would otherwise be left to the intuitions and speculations of the investigator" (p. 390). Therefore, participants who provided their email addresses in the second part (demographic info) of DET, were later emailed and were asked to participate in the procedure. From among the 42 participants emailed, only 8 participants (4 NSs and $4 \mathrm{TLs}$ ) agreed to partake in the interviews.

During the interviews, 8 participants were asked to respond to the DET questionnaires that they had filled out and to explain their language and strategy choice in their verbal complaints recorded in the role plays. The interviews were conducted by the researcher and the participants were asked the following questions: 1) I see that you rated this statement $X$ (one of the ratings in the 5-Likert scale; e.g. very rude, perfectly appropriate, etc.). Why did you give this statement a rating of $\mathrm{X}$ ?; 2) Would you really normally behave the same way in a real-life situation? Could you please explain?; and 3) In your opinion, would all native speakers / all learners of English act in this way in their formal complaints?

The interviews were carried out in the mother tongue of the participants. The questions used in the interview followed the order presented above; however, depending on the informant's responses additional questions were posed to clarify and follow up on the informant's answers. The researcher took detailed notes of the participants' responses to the interview questions, and the information gathered from the interviews was used to provide insights on why learners use certain strategies or linguistic forms in their speech act performance.

\subsection{Data analyses}

Both quantitative and qualitative analyses were carried out in accordance with the research questions posed. First, all participants' responses to the open-ended last part of DETs and role-play transcripts were analyzed according to Murphy and Neu's (1996) formulation focusing on complaint speech act sets and devising the semantic units obtained from the preliminary study. In analyzing the data, the researcher coded the semantic components used in each complaint speech act set as in the following examples: 1) initiators, such as, "Hi", "Good afternoon", and "Excuse me, professor"; 2) establishing context, as in, "I came to discuss my grade"; 3) a request, such as, "Could you explain why my grade is a C?"; and finally 4) conveyance of 
disappointment/dissatisfaction/annoyance, as in, "To be honest, I was very surprised of the grade I received".

Means and standard deviations of NSs' and TLs' DET Likert-scale scores were calculated and then the means were compared using independent sample t-test. Moreover, the third component of their speech act productions in both DETs and roleplays were analyzed. In the third component of the semantic units, participants either used direct requests such as "Can you explain why I got a C?" or indirect requests such as "Could I perhaps find out how the grades were figured?". Frequencies of the participants' direct and indirect requests were calculated in order to explain their linguistic and pragmatic choices regarding appropriate language use and directindirect politeness strategies (Garcia, 1989; Fraser, 1990; Harada, 1996). After DET and role-play transcriptions were coded, frequency counts were carried out for the qualitative analyses. Additionally, using the data gathered from the DET, descriptive analyses such as frequency counts of all 4 components were run in order to account for how the two groups of participants differed linguistically in their formal complaint behavior. In other words, the data gathered from the DETs were both qualitatively and quantitatively analyzed.

In order to account for any variables that affect the language and strategy choice of the participants, correlation analyses were performed. First, the demographic information and other variables such as 'the length of stay' and 'gender' were statistically coded. Later each independent variable was compared with the means of DET scores of the two groups. Results were obtained using independent sample t-tests and one-way ANOVA tests.

The role plays and the interviews were qualitatively analyzed. Once the role plays were transcribed, the coded language and strategy use of the participants were studied in terms of the frequency counts. Similarly, the interviews conducted were analyzed to determine what patterns emerged regarding language strategy use. The analysis of interview data was used to enhance the data gathered from the DETs and the role plays.

\section{Results}

\subsection{Linguistic and pragmatic differences (quantitative)}

There was a significant difference between the DET Likert-scale total scores of Turkish learners of English (TLs) and those of Native Speakers (NSs) [t(274)= -9,53, $\mathrm{p}<.01]$. The mean of NSs scale scores $(\mathrm{M}=37,19)$ was higher than that of TLs $(M=31,40)$. These results may suggest that the NSs find these statements appropriate for formal complaints. On the other hand, TLs think that these statements are less appropriate. In other words, the use of the given statements in formal complaints may be rude for TLs whereas it is more appropriate for NSs. 
Table 1. Independent Sample T-Test Results of the Participants' DET Scale Scores

\begin{tabular}{lllllll}
\hline Participant Groups & $\mathrm{N}$ & $\overline{\mathrm{X}}$ & $\mathrm{S}$ & $\mathrm{df}$ & $\mathrm{t}$ & $\mathrm{p}$ \\
\hline Turkish Learners of English (TLs) & 144 & 31,40 & 5,32 & 274 & $-9,53$ & 0,00 \\
Native Speakers (NSs) & 132 & 37,19 & 4,72 & & & \\
\hline
\end{tabular}

As to the linguistic differences between the native speakers (NSs) and the Turkish learners of English (TLs), the open-ended DET responses were used. In terms of the differences between the pragmatic choices of the two groups, the 3rd component was distinctively analyzed to see the percentages of direct and indirect usages. Only 14 (9.7\%) TLs used direct requests whereas 82 (56.9\%) used indirect requests as a part of their complaining behavior. On the other hand, 62 (47\%) NSs employed direct strategies in complaining while $55(41.6 \%)$ produced indirect requests as the $3 \mathrm{rd}$ complaint component.

The results brought about significant differences in the pragmatic choices in three aspects: a) there was a significantly large difference within the TLs group in terms of direct-indirect strategy use: TLs mostly preferred indirect strategies while complaining; b) there was a significant difference between the two groups in terms of indirect strategies: 9.7\% TLs and 47\% NSs used direct strategies; and finally c) the distribution of participants who used direct strategies and those who used indirect ones were different in the two groups: the majority of TLs used indirect strategies within the group itself (56.9\% indirect - 9.7\% direct) while the number of NSs that used direct strategies was more than those who used indirect ones (41.6\% indirect $47 \%$ direct). Table 2 below illustrates all results related to the linguistic and pragmatic choices of the participants collectively as obtained from DETs.

Table 2. DETs Results as to the Linguistic and Pragmatic Choices of the Participants

\begin{tabular}{llllllll}
\hline & & \multicolumn{2}{l}{$\begin{array}{l}\text { Components } \\
\text { (Linguistic) }\end{array}$} & & \multicolumn{2}{l}{$\begin{array}{l}\text { Strategy Choice } \\
\text { (Pragmatic) }\end{array}$} \\
\cline { 3 - 7 } & & Initiator & Context & Request & Dissatisfaction & Direct & Indirect \\
\hline \multirow{2}{*}{ TLs } & Frequency (n) & 32 & 26 & 96 & 50 & 14 & 82 \\
& Percentage (\%) & 22.2 & 18.1 & 66.7 & 34.7 & 9.7 & 56.9 \\
\multirow{2}{*}{ NSs } & Frequency (n) & 99 & 95 & 117 & 87 & 62 & 55 \\
& Percentage (\%) & 75 & 72 & 88.6 & 65.9 & 47 & 41.6 \\
\hline
\end{tabular}

\subsection{Linguistic and pragmatic differences (qualitative)}

Video-recorded role plays of the participants produced similar results regarding the pragmatic differences between the native speakers (NSs) and the Turkish learners of English (TLs) in formal complaints. As Table 3 below illustrates, when the transcriptions were scrutinized with regard to the four complaint components, it was found out that although the frequencies of component use were similarly high in both groups, the direct-indirect strategy use differed significantly between NSs and TLs. In 
compliance with the results obtained from the quantitative analyses, 6 (50\%) NSs used direct strategies whereas only $4(33.3 \%)$ NSs used indirect requests as a part of their formal complaining. On the other hand, all 4 (100\%) TLs employed indirect strategies in their complaints.

Furthermore, the role-plays showed that NSs were more assertive in formal complaints whereas TLs were more reserved and did not want to offend the professor at any terms. A total of $3 \mathrm{NSs}$ wanted to pinpoint a certain time to meet and talk about the revised grades once the professor agreed to recheck the exam papers. On the other hand, TLs avoided any direct judgments, tended to put the blame on themselves and expressed their gratitude to the professor for his having accepted to review the grades.

Table 3. Results Obtained from Role Plays as to the Linguistic and Pragmatic Choices of the Participants (12 NSs + 4 TLs)

\begin{tabular}{llllllll}
\hline & & \multicolumn{2}{l}{$\begin{array}{l}\text { Components } \\
\text { (Linguistic) }\end{array}$} & & & \multicolumn{2}{l}{$\begin{array}{l}\text { Strategy } \\
\text { Choice } \\
\text { (Pragmatic) }\end{array}$} \\
\cline { 3 - 8 } & & Initiator & Context & Request & Dissatisfaction & Direct & Indirect \\
\hline \multirow{2}{*}{ TLs (4) } & Frequency (n) & 4 & 4 & 4 & 2 & - & 4 \\
& Percentage (\%) & 100 & 100 & 100 & 50 & - & 100 \\
\multirow{2}{*}{ NSs (12) } & Frequency (n) & 11 & 12 & 10 & 11 & 6 & 4 \\
& Percentage (\%) & 91.7 & 100 & 83.3 & 91.7 & 50 & 33.3 \\
\hline
\end{tabular}

Participants' answers to open-ended interview questions also revealed similar results. As an answer to the second interview question, which was 'Would you really normally behave the same way in a real-life situation?', all of the NSs stated that they would act in the same way. This shows that their language production in the roleplays was real-life like. The third question of the interviews asked their opinions on whether all native speakers / all learners of English would act in this way in their formal complaints. The majority of the NSs thought that most native speakers of English would behave as assertive and demanding as they did. They stated that most NSs would believe "it was their right to question the grades if they were not satisfied with what they had got". However, TLs believed that most Turkish people would be as polite as possible to the professor since "it was his choice to review the grades as a superior figure". Therefore, TLs would "avoid any offensive behavior that would make the professor annoyed" such as "blaming him of miscalculation" or "asking him directly to explain why the grade was a C".

\subsection{The age effect on complaints}

Total Likert-scale scores and their means were statistically correlated to the age groups of the participants. The results indicated no significant difference between the Likert-scale scores of Native Speakers (NSs) regarding their age categories [F(2-127) 
$=0,291, \mathrm{p}>.01]$. On the other hand, as the results in Table 4 and 5 indicate, there was a significant difference between those of TLs $[\mathrm{F}(2-141)=7,92, \mathrm{p}<.01]$. In other words, TLs scores differed significantly according to their age groups. Using these results, post-hoc Tukey test was performed to find out between which groups these differences occurred. According to the results of the Tukey test, participants' Likert-scale scores in 18-24 age group $(=31,50)$ and in 25 -30 age group $(=33,75)$ were higher and more positive (in terms of the appropriateness of the complaints) compared to those of the participants who were 31 and above $(=27,25)$.

Table 4. One-way ANOVA Results of the Comparison of TLs' DET Likert Scale Scores According to Age

\begin{tabular}{|c|c|c|c|c|c|c|c|}
\hline Age & & $\begin{array}{l}\text { Source of the } \\
\text { variance }\end{array}$ & $\begin{array}{l}\text { Sum of } \\
\text { squares }\end{array}$ & $\mathrm{df}$ & $\begin{array}{l}\text { Mean of } \\
\text { squares }\end{array}$ & $\mathrm{F}$ & $\begin{array}{l}\text { Significant } \\
\text { Categories }\end{array}$ \\
\hline \multirow{3}{*}{ TLs } & $\begin{array}{l}\text { Between } \\
\text { groups }\end{array}$ & 409,139 & 2 & 204,569 & 7,921 & ,001 & $\begin{array}{l}\text { (18-24 age), } \\
\text { (25-30 age), } \\
\text { (31\&above) }\end{array}$ \\
\hline & $\begin{array}{l}\text { Within } \\
\text { groups }\end{array}$ & 3641,500 & 141 & \multirow[t]{2}{*}{25,826} & & & \\
\hline & Total & 4050,639 & 143 & & & & \\
\hline
\end{tabular}

Table 5. Group Statistics on TLs' Likert-scale Scores According to Age

\begin{tabular}{lllllll}
\hline Age (TLs) & $\mathrm{N}$ & $\overline{\mathrm{X}}$ & $\mathrm{S}$ & $\mathrm{df}$ & $\mathrm{t}$ & $\mathrm{p}$ \\
\hline 18-24 ages & 104 & 31,50 & 5,54 & 25,82 & $-2,61$ &, 001 \\
25-30 ages & 24 & 33,75 & 4,29 & & & \\
31 ages and above & 16 & 27,25 & 1,83 & & & \\
\hline
\end{tabular}

The Likert-scale scores of the Turkish learners changed significantly not only according to their age groups. Younger learners think that the use of the given statements is more appropriate compared to learners aged 31 and above. The oldest of three groups of Turkish learners finds the statements rude. These findings may indicate that Turkish learners are affected by their cultural traits in their complaining behavior.

\subsection{Other demographic factors}

The second part of DET collected further demographic information about TLs on three other factors: 1) proficiency in English, 2) length of stay in target culture, and 3) English learning methodology. These independent variables were statistically coded according to the responses given by the participants. Later total Likert-scale mean scores were statistically correlated to the individual variables. Results showed no significant difference between groups in terms of these three individual factors. In short, none of the three factors above affected the TLs complaint choices.

\subsection{Directness-indirectness in complaints (quantitative)}

Of the 10 statements in DET, statements 1, 3, 5, 8 and 10 used direct requests (e.g. "I was hoping you could explain why I got a C") whereas the statements 2, 4, 6, 7 and 
9 involved indirect requests (e.g. "Would you consider the possibility that there might have been a mistake?") as a part of the complaint in the given scenario. In order to account for the strategy choice of the participants, analyses using the grouped items were performed. First, the means from the total scores of direct items and indirect items were calculated. Later, the means of the scores gathered from the two groups of items ( 5 direct items and 5 indirect items) according to the two groups of participants (TLs and NSs) were compared using paired sample t-test and independent sample ttest.

As the results of paired sample t-tests in Table 6 and 7 show, there was a significant difference between the Turkish learners' (TLs) scores of direct and indirect items $[\mathrm{t}(2-143)=-22,306, \mathrm{p}<.01]$. TLs' Likert-scale scores for indirect items $(=18,00)$ were significantly higher than their scores for direct items $(=13,40)$. In other words, TLs think that it is more appropriate to use indirect statements in formal complaining and that the use of direct requests as a part of complaints is rude. Also, a significant difference was found between the Native speakers' (NSs) scores of direct and indirect items $[\mathrm{t}(2-131)=-10,24, \mathrm{p}<.01]$. NSs' scores given to indirect items $(=19,96)$ were slightly higher than their scores given to direct items $(=17,22)$. However, since the statistical difference between the means of the two Likert-scale scores is small, it should be argued these results may have resulted due to individual differences in the strategy choices of native speaker participants with various nationalities.

Table 6. Paired Sample T-Test Results of the Comparison of TLs' Direct and Indirect Items

\begin{tabular}{lllllll}
\hline Group of items (TLs) & $\bar{X}$ & $\mathrm{X}$ & $\mathrm{S}$ & $\mathrm{df}$ & $\mathrm{t}$ & $\mathrm{p}$ \\
\hline Direct items & 144 & 13,40 & 2,99 & $-22,306$ & 143 & 0,00 \\
Indirect items & 144 & 18,00 & 2,87 & & & \\
\hline
\end{tabular}

Table 7. Paired Sample T-Test Results of the Comparison of NSs' Direct and Indirect Items

\begin{tabular}{lllllll}
\hline Group of items (NSs) & $\mathrm{N}$ & $\overline{\mathrm{X}}$ & $\mathrm{S}$ & $\mathrm{df}$ & $\mathrm{t}$ & $\mathrm{p}$ \\
\hline Direct items & 132 & 17,22 & 2,92 & $-10,24$ & 131 & 0,00 \\
Indirect items & 132 & 19,96 & 2,70 & & & \\
\hline
\end{tabular}

In order to justify the results obtained from the paired sample t-test, independent sample t-test was also performed using the same group of data collectively, comparing the direct and indirect item scores of TLs and NSs. The findings given in Table 8 below indicate similar results. 
Table 8. Independent sample T-Test Results of the Comparison of Direct and Indirect Items According to Participant Groups

\begin{tabular}{|c|c|c|c|c|c|c|c|}
\hline \multicolumn{2}{|c|}{ Item and Participant Groups } & $\mathrm{N}$ & $x$ & $\mathrm{~S}$ & $\mathrm{df}$ & $\mathrm{t}$ & $\mathrm{p}$ \\
\hline \multirow{2}{*}{$\begin{array}{l}\text { Direct } \\
\text { Items }\end{array}$} & TLs & 144 & 13,40 & 2,99 & \multirow[t]{2}{*}{$-10,733$} & \multirow[t]{2}{*}{274} & \multirow[t]{2}{*}{, 000} \\
\hline & $\mathrm{NSs}$ & 132 & 17,22 & 2,92 & & & \\
\hline \multirow{2}{*}{$\begin{array}{l}\text { Indirect } \\
\text { Items }\end{array}$} & TLs & 144 & 18,00 & 2,87 & \multirow[t]{2}{*}{$-5,825$} & \multirow[t]{2}{*}{274} & \multirow[t]{2}{*}{, 000} \\
\hline & $\mathrm{NSs}$ & 132 & 19,96 & 2,70 & & & \\
\hline
\end{tabular}

There was a significant difference between the direct item scores of TLs and NSs $[\mathrm{t}(4-274)=-10,733, \mathrm{p}<.01]$. Likert-scale scores given to direct items by NSs $(=17,22)$ were significantly higher than their scores given to direct items by TLs $(=13,40)$. Hence, TLs think that the use of direct requests as a part of complaints is rude whereas the NSs find direct statement more appropriate than TLs do. Likewise, a significant difference was found between the indirect item scores of Turkish learners $(\mathrm{TLs})$ and native speakers $(\mathrm{NSs})[\mathrm{t}(4-274)=-5,825, \mathrm{p}<.01]$. Attitude scores given to indirect items by NSs $(=19,96)$ were significantly higher than their attitude scores given to direct items by TLs $(=18,00)$.

\subsection{Directness-indirectness in complaints (qualitative)}

Video-recorded role plays of the participants produced similar results regarding the pragmatic differences between the native speakers (NSs) and the Turkish learners of English (TLs) in formal complaints. As Table 9 above illustrates, when the transcriptions were scrutinized with regard to the four complaint components, it was found out that although the frequencies of component use were similarly high in both groups, the direct-indirect strategy use differed significantly between NSs and TLs.

Table 9. Linguistic and Pragmatic Choices of the Participants (Role Plays)

\begin{tabular}{llllllll}
\hline & & \multicolumn{3}{l}{ Components (Linguistic) } & & \multicolumn{2}{c}{ Strategy Choice (Pragmatic) } \\
\cline { 3 - 7 } & & Initiator & Context & Request & Dissatisfaction & Direct & Indirect \\
\hline \multirow{2}{*}{ TLs (4) } & Frequency (n) & 4 & 4 & 4 & 2 & - & 4 \\
& Percentage (\%) & 100 & 100 & 100 & 50 & - & 100 \\
\multirow{2}{*}{ NSs (12) } & Frequency (n) & 11 & 12 & 10 & 11 & 6 & 4 \\
& Percentage (\%) & 91.7 & 100 & 83.3 & 91.7 & 50 & 33.3 \\
\hline
\end{tabular}

In compliance with the results obtained from the quantitative analyses, 6 (50\%) NSs used direct strategies whereas only $4(33.3 \%)$ NSs used indirect requests as a part of their formal complaining. On the other hand, all 4 (100\%) TLs employed indirect strategies in their complaints. Examples of NSs' direct strategy uses and TLs' indirect requests as a part of complaints are presented below as transcribed pieces of utterances:

Turkish Learner 1:

Prof : Okay, what were you expecting?

TL1 : \% .... A! 
Prof : Okay

TL1 : ...because this is my favorite course, I did my best actually so... \% could there be a mistake?

Turkish Learner 2:

TL2 : And you?

Prof : Fine. Thank you.

TL2 : \% my problem is that \% I didn't expect such a low grade in my last paper, last exam and I am very sorry, I'm so sorry, and... I want to learn about your evaluation criteria for the last paper

Turkish Learner 3:

TL3 : Have a nice day first of all....I would like to talk to you about my final grade

Prof : : [Yeah

TL3 : [.... if you have some time... I think I have done a good job in your course and I studied very hard, and as you know \% my project was good and... after all when I got my final grade I was shocked... so I was wondering if you could explain me how the grades were figured

Turkish Learner 4:

TL4 : I was expecting \% much more \% high grade

Prof : Okay, what grade did you get?

TL4 : I got a C... I wonder if you could check my paper again or ... have a look?

Open-ended interview results complied with the quantitative analyses in that all the statements that the TLs rated "rude" or "very rude" were one of the direct statements whereas the ones they rated 'appropriate' or 'perfectly appropriate' were indirect components. Here are the results for each participant:

\section{Turkish Learner 1:}

TL1 rated the 3rd statement 'very rude' because she found the request too direct to be uttered to a professor, who was older and in a superior position then she was. On the other hand, she rated the 6th statement 'perfectly appropriate' since this indirect complaining implied that the mistake might have resulted from the participant not from the professor, if any. She also added that she would not want to sound offensive towards a professor.

\section{Turkish Learner 2:}

TL2 rated the 3rd statement 'rude' because he thought the word 'explain' implied a direct order, which sounded impolite. However, he rated the 4th statement 'perfectly 
appropriate' since this indirect complaining involved a passive structure and it emphasized an indirect request of being informed. He further stated that he would prefer to be respectful towards a professor.

\section{Turkish Learner 3:}

TL3 rated the 3rd and the 10th statements 'rude' since he thought these statements directly accused the professor of deliberately 'mis-grading' the student despite the use of 'please'. In contrast, he rated the 2 nd statement 'perfectly appropriate' since this statement politely emphasize that there might have been a mistake and that its indirect nature implies no direct offense on the professor. He also called attention to the fact that this indirect statement was appropriate to use while speaking to an elder and superior figure.

\section{Turkish Learner 4:}

TL4 rated the 3rd and the 5th statements 'rude' because he thought these statements contained a direct order due to its grammatical structure and word choice, which was impolite. On the contrary, he rated the 2nd and the 7th statements 'appropriate' since these statements politely requested the professor to review the grades although the mistake might possibly have stemmed from the student. He also asserted Turkish culture required indirect strategies due to respect concerns.

\section{Discussion}

The main motivation behind studying complaint speech act sequences of native speakers (NSs) and Turkish learners (TLs) of English was not only to investigate the complaint productions of the two groups linguistically and pragmatically, but also to find out their perceived appropriateness of complaining speech act utterances in terms of directness and indirectness. In this mentioned framework, some significant conclusions were drawn on the basis of the analyses conducted in the present study.

First of all, native English speakers' and Turkish learners' production of complaints reflects a significant difference with respect to a) the linguistic components (semantic formulas) by which the complaints are formulized, b) the pragmatic choices made in complaining with reference to direct and indirect strategies. Secondly, native English speakers' and Turkish learners' perceptions of social appropriateness of direct and indirect complaints also reflect a significant difference. TLs are more reserved and indirect in their complaining behavior compared to NSs. That this may cause problems in interactions between Turkish speakers of English and English native speakers in that NSs may think TL is not assertive enough and they may conclude that there are not adequate reasons even to complain at all. Besides, there may be communication breakdowns (Canale, 1983) in interactions where NSs complain about an issue to TLs in English. TLs may find NSs too rude or too direct, which may be interpreted as impoliteness. Thirdly, the pragmatic preferences made by Turkish 
learners are significantly different from those of native speakers with regard to 'age'. Relatively, older TLs find directness rude in complaining.

Generally, NSs were more assertive and direct whereas TLs were more reserved and indirect in their complaining behavior, but both groups concurred about their opinions regarding polite language use. These findings suggest that the basic need of interlocutors to maintain their own as well as the hearer's face was a motivating factor in the subjects' views on appropriate and polite language use. However, in spite of these similar views regarding politeness, the two groups demonstrated different behaviors in the DETs and the role plays in terms of direct and indirect strategies. What is more, Turkish learners stated that they believed the native speakers would be more direct in their complaining behavior. Thus, it appears that Turkish learners are either not completely successful in translating their declarative knowledge into procedural knowledge or they choose not to do so due to their won cultural routine, which suggest that the TLs are affected by their own culture in formal complaints in English. In Turkish culture, it is commonly rude to pose direct complaints, especially to older people, which suggests that the Turkish learners transfer pragmatic features from their own cultural etiquette. In other words, Turkish learners transfer their own pragmatic strategies into their formal complaining behavior in English. The younger generation in Turkey, however, might be becoming more direct. This may result from the fact that they are more exposed to western cultural values where directness may be perceived as relevance rather than impoliteness.

Pragmatic failure that results from different belief systems (i.e., socio-pragmatic failure) underlying language use is particularly challenging because it requires the learners both as speakers and hearers to adapt to a system of values that might be 'foreign' to them (Benson, 2002). However, the language learner should be given access to the norms/values of the target culture so that he/she is in a position to decide whether to add the new values to the existing system he/she already has, or to disregard the new system. Saville-Troike (1982) and Thomas (1983) caution against enforcing the values of the target culture on language learners, but emphasize the need to provide this information so that learners do not inadvertently commit a faux pas. Thus, according to the findings of this study, Turkish learners would need to have access to information about what an appropriate complaint is so that they are less likely to encounter difficulties in interactions with native speakers. Nonetheless, they should not be forced to use these norms at the expense of conflicting themselves and their own cultural characteristics.

Although learners should be offered explicit and implicit input, the goal of teaching pragmatic practices is not necessarily to encourage all language learners to achieve native-like speech proficiency (Hinkel, 1996). We cannot fully understand what makes learners pragmatically transfer without reference to theories that can account for learners' choice of speech behavior, reasons for their choices and their consequences (Gass \& Selinker, 1992). It is important to understand that individual and subjective processes may have an impact on the second language learner's performance (Bardovi-Harlig et al. 1991; Bardovi-Harlig \& Hartford, 1993; Bardovi-Harlig, 1996; 
Bardovi-Harlig \& Griffin, 2005). A discussion of the phenomenon of pragmatic transfer should include a consideration of possibly conflicting needs such as the need to be pragmatically appropriate, the need to get things done or the need to display individual identity. Language teachers are not to transform language learners into native-speakers, but to inform language learners of the pragmatic choices and their consequences. In other words, learners should be given the knowledge to make an informed choice, which allows them the freedom to express their own values and beliefs.

Language learners should be given tools to use to help them understand what is appropriate and what is not, what is rude and what is polite, and they should be allowed to make their own decisions on how to respond. The learners should be comfortable enough in target language to decide to be rude or polite intentionally rather than inadvertently (Jiang, 2006). In addition, assessment of an ideal native speaker model may remain problematic since pragmatic norms vary within target languages. There is preliminary evidence that pragmatic research has failed to account for "regional and social factors on intra-lingual choices in language use in both pragmatics and dialectology" (Barron, 2005, p. 520). However, it is possible that there exist potential intra-lingual pragmatic factors due to geographical or social variables influencing Turkish participants' verbal behavior. Most Turkish people realize, for example, that the perception of social distance and social dominance, or the perception of what is appropriate verbal behavior in private, official and public spheres may be different for Turkish people in rural regions of the country than for people living in urban areas. Therefore, including intra-lingual pragmatic differences in the language teaching process can prove to be beneficial to the learners as it "can extend their perspective to appreciate many levels of pragmatic variation in both linguistically-close and linguistically-distant cultures" (Barron, 2008, p. 389).

\section{Conclusion}

In reconsidering pragmatic ability as a teaching goal, we must realize that nativelike speech is not always the ultimate objective for all learners (Paikeday, 1985). However, as language educators, we must at least teach learners to use language within an acceptable range of pragmatic appropriateness in the target language. It remains to be examined what instructional options are best to help students in different social environments and what contexts improve their knowledge and skill in using language effectively (Widdowson, 1989). For future studies, by studying developmental speech act performance over time, it may be possible to measure more rigorously the contributions and limitations of formal instruction.

Devised by the researcher and used for the first time in this study as a data collection tool, Discourse Evaluation Task can be a useful instrument for collecting information as to pragmatic behavior of participants as well as their reported perceptions and beliefs. It is both quick and relatively easy to administer thus high in practicality. More prominently, it lends itself to more quantitative analyses with a 5 
Likert-scale evaluation of items as a part of a structured pragmatic scenario. Also, an open-ended question to the same scenario validates scale scores, resulting in better interpretations of responses. Lastly, it ensures more detailed demographic information as to participants. Future studies that will possibly use this newly-born tool will show its further advantages and drawbacks.

The findings of this study are limited to the Turkish population participating in the study. The limited size and the nature of the participant sample do not provide grounds for making broad generalizations reaching beyond this group. Besides, with an attempt to generalize the native speaker patterns on complaining, the Englishspeaking participants of the study include speakers from different countries; however, this may be another limitation since different countries have different cultural interpretations. Additionally, some of the native speaker participants had resided in Turkey for some time. Their exposure to Turkish culture may have affected their linguistic and pragmatic choices in formal complaining. However, the findings do indicate that length of stay in the target environment does not have a significant influence on the pragmatic style choices of Turkish learners of English. Finally, the current study focused on complaint speech act in a formal context between a student and a professor. The results cannot be generalized to different speech acts in semiformal or informal context between people of various power statuses. Therefore, further research calls for studies including other speech acts in various contexts. It is imperative for the sake of language instruction to continue research that provides accurate information regarding how speech acts actually work in communicative situations within various languages and cultures.

\section{References}

Achiba, M.(2003). Learning to request in a second language: Child interlanguage pragmatics. Clevendon: Multilingual Matters.

Arent, R. (1996). Sociopragmatic decisions regarding complaints by Chinese learners and NSs of American English. Hong Kong Journal of Applied Linguistics, 1(1), 125-147.

Bardovi-Harlig, K. (1996). Pragmatics and language teaching: Bringing pragmatics and pedagogy together. In Bouton, L. (Ed.) Pragmatics and language learning (pp. 21-39). Urbana, II.

Bardovi-Harlig, K \& Griffin, R. (2005). L2 pragmatic awareness: Evidence from ESL classroom. System, 33, 401-415.

Bardovi-Harlig, K., Hartford, B., Mahan-Taylor, R., Morgan, M. J. \& Reynolds, D. W. (1991). Developing pragmatic awareness: Closing the conversation. ELT Journal, 45(1), 4-15.

Bardovi-Harlig, K. \& Hartford, B. (1993). Learning the rules of academic talk: A longitudinal study of pragmatic development. Studies in Second Language Acquisition, 15, 279-304.

Barron, A. (2005). Variational pragmatics in the foreign language classroom. System 33 (3), 519-536.

Barron, A. (2003). Acquisition in interlanguage pragmatics: Learning how to do things with words in a study abroad context. Amsterdam/Philadelphia: John Benjamins. 
Barron, A. (2008). Contrasting request in inner circle Englishes: a study in variational pragmatics. In Martin Putz, M. \& Neff-van Aertselaer, J. (Eds.), Developing contrastive pragmatics: Interlanguage and cross-cultural perspectives (pp.46-49). Walter de Gruyter.

Beebe, L., \& Cummings, M. (1985). Speech act performance: A function of data collection procedure. Paper presented at the TESOL '85, New York.

Beebe, L., \& Cummings, M. (1996). Natural speech act data versus written questionnaire data: How data collection method affects speech act performance. In S. Gass \& J. Neu (Eds.), Speech acts across cultures (pp. 64-86). Berlin: Mouton.

Benson, C. (2002). Transfer/cross-linguistic influence. English-Language Teaching Journal, 56(1), 68-70.

Bergman, M. \& Kasper, G., (1993). Perception and performance in native and nonnative apology. In G. Kasper \& S. Blum-Kulka (Eds.), Interlanguage pragmatics (pp.82-107). Oxford: Oxford University Press.

Bialystok, E. (1993). Symbolic representation and attentional control in pragmatic competence. In G. Kasper and S. Blum-Kulka (Eds.), Interlanguage pragmatics (pp.82-107). New York: Oxford University Press.

Blum-Kulka, S. (1982). Learning how to say what you mean in a second language: A study of the speech act performance of learners of Hebrew as a second language. Applied Linguistics, 3, 29-59.

Blum-Kulka, S. (1983). Interpreting and performing speech acts in a second language: A crosscultural study of Hebrew and English. In N. Wolfson and E. Judd (Eds.), Sociolinguistics and language acquisition (pp.36-55). New York: Newbury House.

Blum-Kulka, S. (1991). Interlanguage pragmatics: The case of requests. In R. Phillipson, E. Kellerman, L. Selinker, M. Sharwood Smith, \& M. Swain (Eds.), Foreign/second language pedagogy research (pp. 255-272). Clevedon, UK: Multilingual Matters.

Blum-Kulka, S. \& Olshtain, E. (1986). Too many words: Length of utterance and pragmatic failure. Studies in Second Language Acquisition, 8, 165-179.

Brown, P. \& Levinson, S. (1987). Politeness: Some universals in language usage. Cambridge: Cambridge University Press.

Canale, M. (1983). From communicative competence to communicative language pedagogy. In J.D. Richards \& R.W. Schmidt (Eds), Language and communication (pp.2-29). London: Longman.

Cohen, A. (1996a). Developing the ability to perform speech acts. Studies in Second Language Acquisition, 18, 253-267.

Cohen, A. (1996b). Investigating the production of speech act sets. In S. Gass and J. Neu (Eds.), Speech act across cultures: Challenges to communication in a second language (pp.21-43). Berlin: Mouton.

Cohen, A. (1996c). Speech Acts. In S. L. McKay, and N. H. Hornberger (Eds.), Sociolinguistics and language teaching (pp. 383-420). Cambridge: Cambridge University Press.

Cohen, A., \& Olshtain, E. (1981). Developing a measure of sociocultural competence: The case of apology. Language Learning, 31(1), 113-134.

Du, J. S. (1995). Performance of face-threatening acts in Chinese: Complaining, giving bad news, and disagreeing. In G. Kasper (Ed.), Pragmatics of Chinese as a native and target language (pp. 165-206). Manoa, Hawai'i: University of Hawai'i Press.

Ellis, R. (1992). Learning to communicate in the classroom: A study of two language learners' requests. Studies in Second Language Acquisition, 14(1), 1-23.

Félix-Brasdefer, C. (2007). Pragmatic development in the Spanish as a FL classroom: A crosssectional study of learner requests. Intercultural Pragmatics 4, 253-286. 
Flores Salgado, E. (2011). The pragmatics of requests and apologies: Developmental patterns of Mexican students. John Benjamins, Amsterdam/Philadelphia.

Fraser, B. (1990). Perspectives on politeness. Journal of Pragmatics, 14, 219-236.

Garcia, C. (1989). Apologizing in English: Politeness strategies used by native and normative speakers. Multilingua, 8, 3-20.

Gass, S. \& Selinker, L. (1992). Language transfer in language learning. Philadelphia: John Benjamins Publishing Company.

Göy, E., Zeyrek, D. \& Otcu, B. (2012). Developmental patterns in internal modification of requests: a quantitative study on Turkish learners of English. In M. EconomidouKogetsidis, \& H. Woodfield (Eds.), Interlanguage request modification. (pp. 51-6). Amsterdam/Philadelphia: John Benjamins.

Harada, Y. (1996). Judgments of politeness in L2 acquisition. Working Papers in Linguistics, 21, 39-56.

Hartford, B. S., \& Bardovi-Harlig, K. (1992). Experimental and observational data in the study of interlanguage pragmatics. Pragmatics and Language Learning, 3, 33-52.

Hassall, T. (2003). Requests by Australian learners of Indonesian. Journal of Pragmatics 35, 1903-1928.

Hinkel, E. (1996). When in Rome: Evaluations of L2 pragmalinguistic behaviours. Journal of Pragmatics, 26(1), 51-70.

House, J. \& Kasper, G. (1987). Interlanguage pragmatics: Requesting in a foreign language. In W. Lörscher and R. Schulze (Eds.), Perspectives on language in performance, 2 (pp.12501288). Tübingen: Narr.

Jiang, X. (2006). Suggestions: What should ESL students know? System, 34, 36-54.

Johnston, B., Kasper, G. \& Ross, S. (1994). Effects of Rejoinders in Production Questionnaires, University of Hawaii Working Papers in ESL, 13(1), 121-143.

Kachru, Y. (1991). Speech acts in world Englishes: Toward a framework for research. World Englishes 10(3), 299-306.

Kasper, G. (2001). Classroom research on interlanguage pragmatics'. In K. Rose and G. Kasper (Eds) Pragmatics in language teaching. (pp. 33-62). Cambridge University Press.

Kasper, G. \& Blum-Kulka, S. (1993). Interlanguage pragmatics. New York: Oxford University Press.

Kasper, G. \& Rose, K.R. (2001). Pragmatics in language teaching. New York: Cambridge University Press.

Kim, J. (1995). Could you calm down more?: Requests and Korean ESL learners. Working Papers in Educational Linguistics, 11(2), 67-82.

Márquez Reiter, R. (2000). Linguistic politeness in Britain and Uruguay: A contrastive analysis of requests and apologies. Amsterdam, Netherlands: John Benjamins Publishing.

Meier, A. J. (1998). Apologies: What do we know? International Journal of Applied Linguistics, 8(2), 215-231.

Mizuno, K. (1996). Interlanguage pragmatics of requests: The case of Chinese learners of Japanese. Gengo Bunka Ronsyuu, 17(2), 91-106.

Murphy, B. \& Neu, J. (1996). My grade's too low: The speech act set of complaining. In S.M.Gass \& J. New (Eds). Speech acts across cultures: Challenges to communication in a second language (191-216). New York: Mounton de Gruyter.

Novick, R. (2000). Politeness and rationality. Amsterdam: J. Benjamin Publishing Company.

Olshtain, E., \& Cohen, A. (1983). Apology: A speech-act set. In N. Wolfson \& E. Judd (Eds.), Sociolinguistics and language acquisition (pp. 18-35). New York: Newbury House. 
Otcu, B. \& Zeyrek, D. (2008). Development of requests: a study of Turkish learners of English. In M. Puetz \& J. Neff Van Aertselaer (Eds.), Contrastive Pragmatics: Interlanguage and cross-Cultural perspectives (pp. 265-300). Mouton de Gruyter, Berlin/New York,

Paikeday, T. M. (1985). The native speaker is dead. Toronto and NY: Paikeday Publishing Co.

Saville-Troike, M. (1982). The ethnography of communication. Oxford: Basil Blackwell

Schauer, G. (2004). May you speak louder maybe? Interlanguage pragmatic development in requests. In S.H. Foster-Cohen, M. Sharwood-Smith, A. Sorace \& M. Ota (Eds.), EUROSLA Yearbook 4, (pp. 253-273). Amsterdam/Philadelphia: John Benjamins.

Searle, J. (1969). Speech acts. Cambridge: Cambridge University Press.

Seliger, H., and Shohamy, E. (1989). Second language research methods. New York: Oxford University Press.

Taguchi, N. (2011). Teaching pragmatics. Trends and issues. Annual Review of Applied Linguistics, 31, 289-310.

Taguchi, N. (2012). Context, individual differences, and pragmatic competence. Multilingual Matter.

Taguchi, N. (2015). Instructed pragmatics at a glance: Where instructional studies were, are, and should be going. State-of-the-art article. Language Teaching, 48, 1-50.

Takahashi, T., and Beebe, L. (1987). The development of pragmatic competence by Japanese learners of English. JALT Journal, 8, 131-155.

Tanck, S. (2002). Speech Act Sets of Refusal and Complaint: A comparison of Native and NonNative English Speakers' Production. Studies in Second Language Acquisition, 13, 65-81.

Thomas, J. (1983). Cross-cultural pragmatic failure. Applied Linguistics, 4, 91-112.

Widdowson, H. (1989). Knowledge of language and ability for use. Applied Linguistics, 10(2), 128-137.

Wolfson, N. (1986). Research methodology and the question of validity. TESOL Quarterly, 20(4), 689-699.

Woodfield, H. (2010). What lies beneath?: Verbal report in interlanguage requests in English. Multilingua, 29, 1-27.

Woodfield, H. (2012). "I think maybe I want to lend the notes from you": Development of request modification in graduate learners. In M. Economidou-Kogetsidis \& H. Woodfield (Eds), Interlanguage request modification (pp.9-49). J.Benjamins, Amsterdam/Philadelphia

\section{Copyrights}

Copyright for this article is retained by the author(s), with first publication rights granted to the Journal.

This is an open-access article distributed under the terms and conditions of the Creative Commons Attribution license (CC BY-NC-ND) (http://creativecommons.org/licenses/by-nc-nd/4.0/).

\section{Appendix A. Discourse Evaluation Task}

Read the situation below. 10 possible responses to complete the rest of the dialog between the professor and the student have been listed. Using the scale given after each question, evaluate each response with regard to the extent you think it would be socially acceptable/appropriate for the student to say. In reading these responses, please assume that no irony or sarcasm is expressed in them and that they are uttered with basically "neutral" intonation. 


\section{Situation:}

The speaker (the same gender as yours), a university student, received his/her final grade for a course. The student was shocked that Professor Evans (50 years old) gave him/her a C. The class was one of the student's favorites, and he/she had studied very hard. The student got an A on his/her final exam/project, so does not understand why the final grade was so low. The student knocks on the door of the professor's office:

Prof. Evans : Come in.

The Student : Good afternoon,

Professor Evans. I would like to

talk about my final grade....

\begin{tabular}{|c|c|c|c|c|}
\hline $\begin{array}{l}\text { VERY } \\
\text { RUDE }\end{array}$ & RUDE & $\begin{array}{c}\text { NOT } \\
\text { DECIDED }\end{array}$ & APPROPRIATE & $\begin{array}{l}\text { PERFECTLY } \\
\text { APPROPRIATE }\end{array}$ \\
\hline & & & & \\
\hline & & & & \\
\hline & & & & \\
\hline & & & & \\
\hline & & & & \\
\hline & & & & \\
\hline & & & & \\
\hline & & & & \\
\hline & & & & \\
\hline & & & & \\
\hline & & & & \\
\hline & & & & \\
\hline
\end{tabular}

1. I was hoping you could explain why I got a $\mathrm{C}$.

2. Would you consider the possibility that there might have been a mistake?

3. Please explain why I got a $\mathrm{C}$.

4. Could I perhaps find out how the grades

were figured?

5. Can you explain why my final grade was so low?

6. Can I see my final exam paper, please?

7. Could you explain what has gone wrong - in my studies?

8. I was not expecting a grade that low.

8. Could you please recalculate?

9. Could you spare five minutes to show

9. me my overall grades?

10. Can I find out why I got a C?

Now, consider that you are the student in the scenario above. You have just knocked the professor's door to complain about your final grade. Complete the scenario by writing what you would say.

Professor Evans : Come in.

You 